\title{
Habitat requirements and population estimate of the endangered Ecuadorian Tapaculo Scytalopus robbinsi
}

\author{
CLAUDIA HERMES, JEROEN JANSEN and H. MARTIN SCHAEFER
}

\begin{abstract}
Summary
The Chocó-Tumbesian region of western Ecuador is one of the 25 global biodiversity hotspots harbouring high numbers of endemic species, which are heavily threatened by habitat loss and fragmentation. Moreover, ongoing climate change in the tropics drives species uphill as lowerlying areas are becoming constantly drier. Such upslope movement can pose major challenges for less mobile species, such as understorey birds which are confined to mature forests and unable to cross habitat gaps. Consequently, these species are threatened by a combination of upslope range shifts and forest fragmentation. In our study, we investigated population numbers and habitat requirements of the Ecuadorian Tapaculo Scytalopus robbinsi, which is endemic to the premontane cloud forests of south-western Ecuador. Comparing the microhabitat structure within territories with control sites revealed that Ecuadorian Tapaculos prefer old secondary forests. Moreover, connectivity between forest fragments was the strongest predictor of the presence of territories within them. We estimated the mean upslope shift of the distribution range as $100 \mathrm{~m}$ per decade and developed a model of habitat availability for the revised range. Extrapolating the number of territories from the study area to the distributional range of the Ecuadorian Tapaculo showed that the global population size is smaller than previously assumed. Our results suggest that the Ecuadorian Tapaculo is strongly affected by forest loss and degradation. Therefore, to prevent a continuing decline in population numbers or even extinction, conservation measures focusing on restoring connectivity between fragments and increasing habitat quality and quantity for the remaining populations need to be prioritised.
\end{abstract}

\section{Introduction}

The pre-montane cloud forests in the Tumbes-Chocó-Magdalena region of western Ecuador and Colombia are considered a global biodiversity hotspot (Myers et al. 2000), where extraordinarily high numbers of endemic species are facing a severe loss of habitat. While only about $25 \%$ of the original extent of primary vegetation remains, the region harbours highly diverse and partly endemic plant and animal communities (Myers et al. 2000). Annual deforestation rates of $1.43 \%$ are driving many of the hotspot's endemic species to the brink of extinction (Brooks et al. 2002).

The environmental distress that species in the Tumbes-Chocó-Magdalena area are facing can deteriorate further due to climate change. Human-induced warming of the atmosphere is altering the level of cloud formation, causing an upslope shift of the cloud bank (Still et al. 1999, Foster 2001). Thus, the increasingly dry conditions in the lower-lying cloud forests result in an upward range shift of tropical montane plant and animal communities (Pounds et al. 1999, Foster 2001, LaVal 2004, Parmesan 2006, Feeley et al. 2011, Freeman and Freeman 2014, MoruetaHolme et al. 2016). This shift does not only generate a loss of original habitat, but can even cause 
the extinction of species confined to mountain tops (Rull and Vegas-Vilarrúbia 2006, Raxworthy et al. 2008, Nogué et al. 2009). Moreover, drier and hotter conditions in the lower areas can form dispersal barriers for some species and, as a consequence, disrupt linkages between populations. Reduced connectivity between populations diminishes their genetic diversity (Epps et al. 2005, Coulon et al. 2006, Segelbacher et al. 2010) and thus restricts a species' potential to adapt to changing environmental conditions (Keller and Waller 2002, Beissinger et al. 2008). The rising cloud bank, the loss of habitat and the reduction in connectivity between populations can act synergistically as drivers of an extinction vortex for cloud forest species (Fagan and Holmes 2006, Brook et al. 2008). A model revealed that approximately one third of the Tumbes-ChocóMagdalena endemics will become extinct if an additional 1,00o $\mathrm{km}^{2}$ of habitat is lost, which ranks the region among the biodiversity hotspots most prone to species loss in the short term (Brooks et al. 2002).

Within the tropical avifauna, endemic insectivorous birds are especially threatened by extinction (Duncan and Blackburn 2004, Sodhi et al. 2004). One example for such a species is the Ecuadorian Tapaculo, also known as El Oro Tapaculo Scytalopus robbinsi, Rhinocryptidae. It was first described by Krabbe and Schulenberg (1997) as an understorey bird confined to wet forests in south-western Ecuador. So far, little is known about the Ecuadorian Tapaculo's population size, habitat requirements or distribution range. It is assumed that the species, being forest dependent and reluctant to cross open areas (Krabbe and Schulenberg 1997), is vulnerable to the degradation, fragmentation and loss of its habitat, which is why the species is classified as 'Endangered' by IUCN.

Being endemic to the Tumbes-Chocó-Magdalena hotspot, the Ecuadorian Tapaculo is affected by the deforestation and the upshift in the cloud bank that are characteristic for the region. It is probable that the above-mentioned environmental pressures have strong effects on the population size and the extent of the distribution of the species. Due to ongoing deforestation, the size of the population is thought to decrease rapidly (Birdlife International 2016). Drier conditions in its habitat due to an rising cloud base have potentially negative impacts on the species, as it favours the most humid areas (Krabbe and Schulenberg 1997). The similarly endangered El Oro Parakeet Pyrrhura orcesi, which occupies the same range as the Ecuadorian Tapaculo, has shifted its altitudinal range upwards at a rate of about $200 \mathrm{~m}$ per 30 years (Klauke et al. 2016). Thus, it is possible that the Ecuadorian Tapaculo is currently undergoing a similar altitudinal shift.

In this study, we aimed to assess the effects of habitat fragmentation caused by deforestation and the rising cloud bank on the distribution range of the Ecuadorian Tapaculo, on its population size and on the availability of habitat for the species. At a small scale, we evaluated the habitat preferences of the Ecuadorian Tapaculo by comparing microhabitat structure, i.e. fine-scale features of the habitat within territories with control plots. Specifically, we tested the hypothesis that the Ecuadorian Tapaculo is heavily threatened by habitat degradation. Accordingly, on a medium scale, we expect the species to be restricted to mature forests or older secondary stands. Alternatively, the species is more tolerant towards habitat degradation and therefore less threatened than assumed by BirdLife International. In this case, we expect to find their territories also in young successional forests.

On a large scale, we assessed the macrohabitat structure in the southern part of the distribution range of the Ecuadorian Tapaculo in terms of the configuration of the remaining forest patches in a landscape context. Specifically, we quantified the area, shape and connectivity of forests, as these are key drivers of the abundance of fragmentation-sensitive species (Noss and Harris 1986). The analyses allowed us to assess species-specific habitat requirements, i.e. to define the preferences of Ecuadorian Tapaculos for a certain microhabitat and macrohabitat structure. Moreover, we evaluated whether the remaining forests provide suitable habitat for Ecuadorian Tapaculos by meeting their specific habitat requirements. To make the first estimate of the global population size based upon field data, we developed a patch occupancy model. During an intensive survey in south-western Ecuador, we determined the number of territories and their density and extrapolated these values to the model area and to the global range. 


\section{Methods}

\section{Study species and study site}

The Ecuadorian Tapaculo is a globally threatened species listed as 'Endangered' by IUCN. It is endemic to the western slopes of the Andes in south-western Ecuador (Figure 1 ). The Ecuadorian Tapaculo was described as occurring in a range of $1,200 \mathrm{~km}^{2}$ at elevations between $700 \mathrm{~m}$ and $1,250 \mathrm{~m}$, preferring the most humid areas in the undergrowth of wet forests (BirdLife International 2016). There is evidence that the range of the species stretches about $55 \mathrm{~km}$ farther to the north than previously assumed: In February 2015, a territory of the Ecuadorian Tapaculo was found in northern Cañar province (N. K. Krabbe and F. Sornoza, personal communication).

Tapaculos in general are poor flyers and move around mainly by hopping, walking or short distance flights (Reid et al. 2004, Castellón and Sieving 2006). Ongoing loss and fragmentation of habitat are presumed to pose a major threat to the remaining populations. The global population of the Ecuadorian Tapaculo is unknown. BirdLife International (2016) estimated the population size between 2,500 and 9,999 mature individuals, based on the potential extent of occurrence of the Ecuadorian Tapaculo and on a previous estimate of the population size of an unrelated species with a similar range (A. Symes pers. comm.). In view of rapid habitat loss, the global population of the Ecuadorian Tapaculo is feared to be decreasing at an alarming pace (BirdLife International 2016).

The species' distribution range is characterised by a mosaic of patchily distributed forest fragments, which are mostly smaller than 100 ha (Robbins and Ridgely 1990, Freile and Santander 2005). From 2005 to 2010 , the deforestation rate in Ecuador was $1.89 \%$, which is the highest rate in South America (FAO 2010). The main causes for the conversion of remaining forests are the intensification of agriculture and forest clearance for livestock (BirdLife International 2016). Already 20 years ago natural vegetation persisted only on steep slopes unsuitable for cattle pastures or agriculture (Best and Kessler 1995). There is only one protected site within the Ecuadorian Tapaculo's distribution range, the private Buenaventura Reserve $\left(\mathrm{S}_{3}, 655^{\circ}, \mathrm{W}_{79}, 744^{\circ}\right)$, owned by the Ecuadorian NGO Fundación Jocotoco. The prevailing vegetation types within the reserve are secondary forests which are separated by areas of abandoned pasture.

\section{Territory identification}

Field work was carried out between December 2013 and May 2014, between October 2014 and January 2015 and between September and November 2015 in $190 \mathrm{~km}^{2}$ of the southern part of the Ecuadorian Tapaculo's distribution range, with the Buenaventura Reserve as core area (Figure 2). We searched in forests in elevations between $600 \mathrm{~m}$ and $1,700 \mathrm{~m}$ for territories of Ecuadorian Tapaculos. In order to survey the greatest possible area within a forest fragment, we established transects parallel to the valley, with a distance of $50-100 \mathrm{~m}$ between transects. Territories were located using tape recordings of the song of male Ecuadorian Tapaculos. The recordings were played every $50 \mathrm{~m}$ with an $8 \mathrm{~W}$ portable playback speaker (Funbox, Intenso, Germany). Tapaculos are known to show year-round strong territorial responses to potential intruders by responding with territorial singing or closely approaching the playback (Sieving et al. 1996, De Santo et al. 2002). We estimated the distance in which we would hear an individual answering to our playback to be $60 \mathrm{~m}$. After 2 min of playback, we waited for 5 min for any reaction (i.e. singing or approaching to the playback), and repeated this cycle three times in total. To make sure that we did not miss an individual which might have been less responsive at a given time, each transect was revisited at least three times during the field season, with intervals of at least one week. For each located territory, we marked coordinates and elevation with a GPS (Oregon 550, Garmin Ltd., USA) for subsequent assessment of microhabitat structure and patch occupancy analyses. 


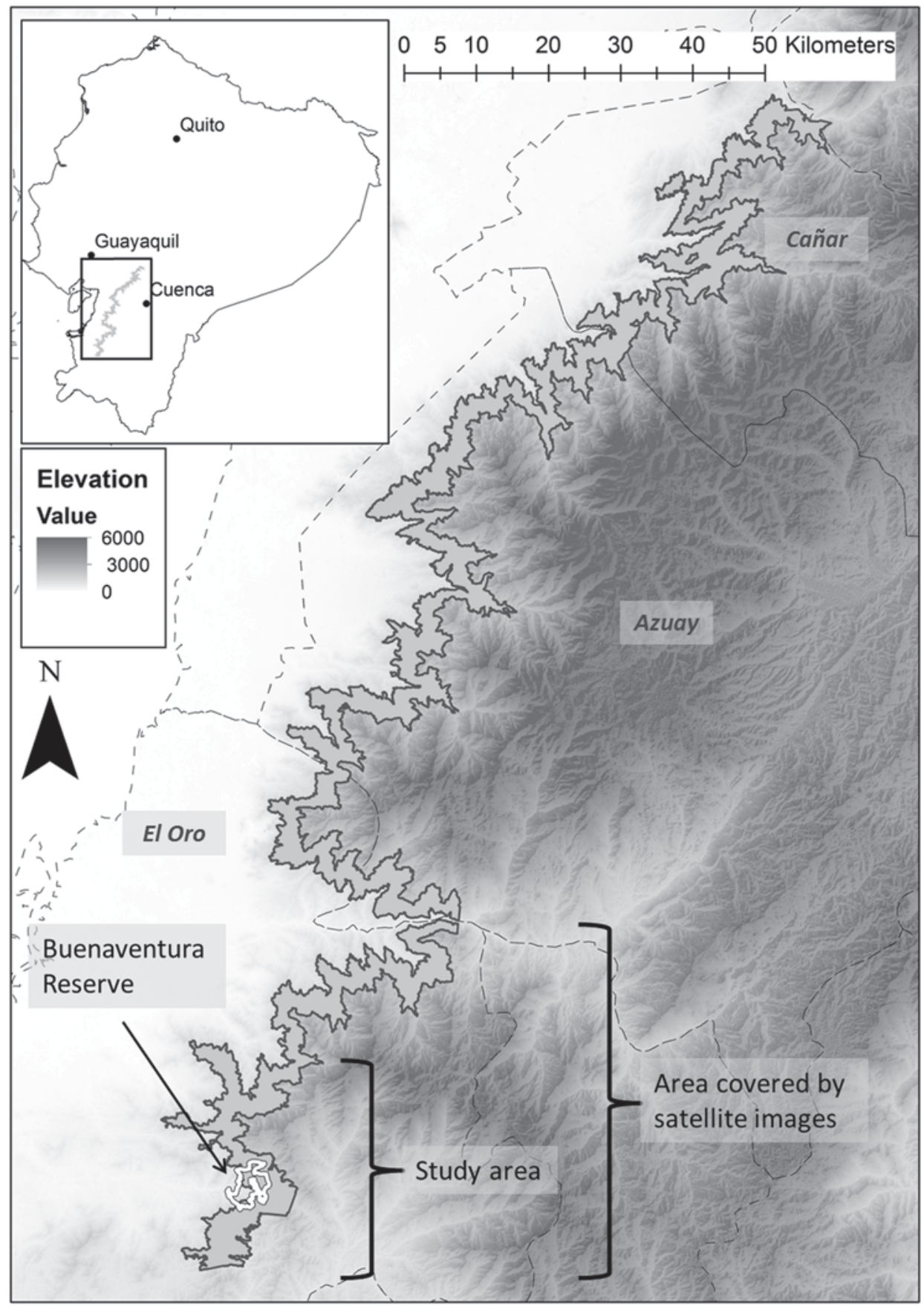

Figure 1 . Distribution range of the Ecuadorian Tapaculo. The species occurs in premontane cloud forests and was found only in an elevation between $850 \mathrm{~m}$ and 1,500 $\mathrm{m}$ (indicated by the black line). Field work was carried out in our study area in the southern part of the distribution range, with the Buenaventura Reserve in the south being the only well-protected site within the area. The satellite images cover about one-third of the distribution range. 


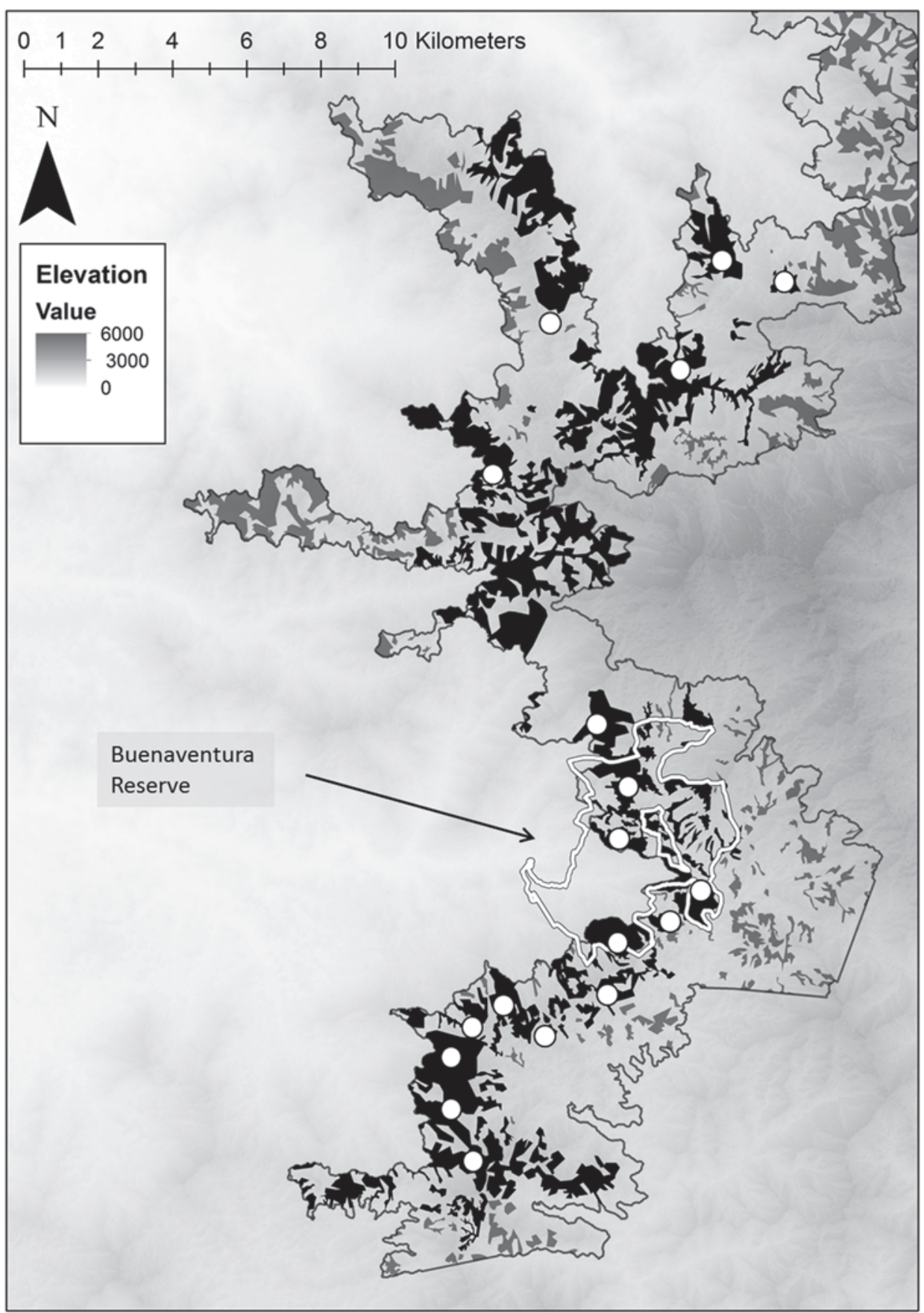

Figure 2. Detailed map of the study area. Forest fragments in the Ecuadorian Tapaculo's elevational range were mapped from satellite images of the area. Fragments where we analyzed microhabitat structure are depicted in black, while forests that were not analyzed are shown in grey. White dots roughly indicate the locations of the territories of Ecuadorian Tapaculos. The Buenaventura Reserve is indicated by the bolt white line. 


\section{Analysis of microhabitat structure at a small scale}

In order to investigate the habitat requirements of the Ecuadorian Tapaculo, we assessed microhabitat characteristics of 28 territories and 36 control plots in the Buenaventura Reserve. Using Quantum GIS 2.0, control plots were generated as random points in forested areas above $700 \mathrm{~m}$ within the reserve, at places where Ecuadorian Tapaculos were not observed. Moreover, we recorded the microhabitat structure in 44 territories and 73 randomly selected control plots in forest fragments outside the Buenaventura Reserve (Figure 2). On one hand, this enabled us to assess whether the microhabitat preferences found inside the Buenaventura Reserve apply also to a much larger area. On the other hand, it allowed us to later evaluate habitat suitability in fragments where we did not detect territories. Depending on fragment size, we analysed between one and 18 plots per fragment. Minimum distance between fragments was $10 \mathrm{~m}$.

The exact territory size of the Ecuadorian Tapaculo is unknown. Observing the movements of four territorial birds and measuring the area in which we obtained their territorial response yielded a territory size of 0.1 ha to 0.5 ha (see also Klemann Jr. and Vieira 2013). We therefore used a conservative estimated value of $\sim$ O.I ha (simplified as a square with side length of $33 \times 33 \mathrm{~m}$ ) as standard territory size. For each territory, we analysed five randomly selected subplots measuring $5 \times 5 \mathrm{~m}$. To characterise the microhabitat structure, we chose 11 habitat parameters (see Table I and online supplementary material for parameter descriptions) that are commonly used to describe the structure of tropical forests in different successional stages (e.g. Montgomery and Chazdon 2001, DeWalt et al. 2003, Faria et al. 2009), or are of special importance for other species of tapaculos (De Santo et al. 2002, Reid et al. 2004, Amico et al. 2008). These parameters were assessed within each subplot. To obtain one value per plot for each variable, we calculated the arithmetic mean for the five subplots.

\section{Evaluation of habitat requirements and habitat suitability at a medium scale}

To evaluate the Ecuadorian Tapaculo's habitat requirements, we compared the microhabitat structure of the 36 control plots and 28 territories that were analysed in 21 forest fragments in the

Table 1. Variables used to assess and compare habitat characteristics of 28 territories of Ecuadorian Tapaculos and 36 control plots within the Buenaventura Reserve $\left(\mathrm{S}_{3}, 655^{\circ}, \mathrm{W} 79,744^{\circ}\right)$, with the loadings, eigenvalues and variance of the first four principal components (threshold: 0.375 ; bold font).

\begin{tabular}{|c|c|c|c|c|c|}
\hline \multicolumn{2}{|l|}{ Variables } & \multicolumn{4}{|c|}{ Loadings } \\
\hline Habitat variable & Variable description & $\mathrm{PC}_{1}$ & $\mathrm{PC}_{2}$ & $\mathrm{PC}_{3}$ & $\mathrm{PC}_{4}$ \\
\hline Inclination $\left[{ }^{\circ}\right]$ & Mean inclination & 0.148 & -0.394 & -0.329 & -0.119 \\
\hline Tree height $[\mathrm{m}]$ & Maximum tree height & -0.128 & -0.465 & -0.111 & -0.296 \\
\hline $\mathrm{DBH}[\mathrm{cm}]$ & $\begin{array}{l}\text { Diameter in breast height, for all trees } \\
\text { with } \mathrm{DBH} \geq 10 \mathrm{~cm}\end{array}$ & -0.295 & -0.422 & 0.430 & 0.018 \\
\hline $\mathrm{TBA}\left[\mathrm{m}^{2}\right]$ & $\begin{array}{l}\text { Tree basal area, for all trees with } \\
\qquad \mathrm{DBH} \geq 10 \mathrm{~cm}\end{array}$ & -0.320 & -0.329 & 0.503 & 0.012 \\
\hline Number of trees & Number of trees with $\mathrm{DBH} \geq 10 \mathrm{~cm}$ & -0.275 & -0.004 & -0.242 & -0.656 \\
\hline Density in $0-50 \mathrm{~cm} \mathrm{[ \% ]}$ & Percentage of vegetation in this layer & 0.390 & 0.021 & 0.410 & -0.274 \\
\hline Density in $50-100 \mathrm{~cm}[\%]$ & Percentage of vegetation in this layer & 0.466 & -0.174 & 0.167 & -0.010 \\
\hline Density in $100-150 \mathrm{~cm}[\%]$ & Percentage of vegetation in this layer & 0.446 & -0.157 & 0.093 & 0.060 \\
\hline Woody debris & $\begin{array}{l}\text { Presence of coarse woody debris } \\
\text { (fallen trunks, branches etc.) }\end{array}$ & 0.216 & -0.364 & -0.318 & -0.105 \\
\hline Streams & Presence of streams or water runs & 0.116 & -0.373 & -0.144 & 0.374 \\
\hline Canopy density [\%] & $\begin{array}{l}\text { Percentage of the sky obscured by } \\
\text { vegetation }\end{array}$ & -0.262 & -0.126 & -0.238 & 0.487 \\
\hline Eigenvalue & & 3.183 & 2.340 & 1.366 & 1.042 \\
\hline Variance & & 28.94 & 21.28 & 12.42 & $9 \cdot 47$ \\
\hline
\end{tabular}


Buenaventura Reserve. Microhabitat variables differed in their numerical range (e.g. $3-47^{\circ}$ in "inclination" compared to 10-50 $\mathrm{m}$ in "tree height") and were z-standardised before the analysis. To limit the number of variables, we conducted a principal component analysis (PCA) with the standardised mean values and used the first four principal components (PCs) for a logistic regression model. In the model, we entered the presence or absence of a territory in a plot as the dependent variable and the PCs describing the habitat characteristics as independent variables. To assess differences in microhabitat structure between territories and control plots, we carried out Mann-Whitney U-tests with the PCs which in the logistic model yielded the largest effects on whether a fragment was occupied by a territory.

To assess the habitat quality in a larger area outside of the Buenaventura Reserve, we carried out a linear discriminant analysis (LDA) for 44 territories and 73 control plots in a total of 64 forest fragments in the study area (Figure 2). The two variables "Tree Basal Area" and "Vegetation density in 50-100 cm" had to be excluded from the analysis, as they were strongly correlated with other variables $(r>0.8, P<0.001)$. We then performed a leave-one-out cross-validation of the LDA to reassess group membership. The cross-validation provided a posterior value for the probability of a given plot to be classified as a territory. This value was used as a proxy for the plot's quality as habitat for the Ecuadorian Tapaculo in the following estimation of the population size. Moreover, the LDA allowed us to identify suitable habitat in areas that were not occupied by territories.

\section{Analysis of land cover and connectivity on a medium scale}

Landscape heterogeneity influences the abundance and population viability of fragmentationsensitive species (Noss and Harris 1986). As explained above, the Ecuadorian Tapaculo's distributional range is characterised by a variety of small, disconnected forest fragments separated by large areas of agricultural plantations or cattle pastures. To quantify the amount of remaining forest patches, we applied remote sensing and geographic information system (GIS) analyses. Geo-referenced satellite images (RapidEye, Blackbridge, Germany) of the southern part of the Ecuadorian Tapaculo's distributional range taken between 2010 and 2013 with a resolution of $5 \mathrm{~m}$ were used as a template to manually create a map of forested habitats $\geq 0.1$ ha in ArcMap 10.2 (Figure 2). The satellite images covered about $345 \mathrm{~km}^{2}$ of the southern end of the Ecuadorian Tapaculo's known total range (Figure I). As the Ecuadorian Tapaculo is restricted to forests, we did not distinguish between other land cover types such as pastures or shrubby habitat and classified them for simplicity as a matrix of unsuitable habitat. To assess the amount and shape of the forest fragments in a landscape context, we quantified the following landscape metrics of the fragments: patch size, fragment compactness, and connectivity. We calculated the index of fragment compactness as forest area divided by perimeter to account for a different complexity of fragments and different extents of core vs. edge-affected areas (e.g., a fragment with a rounded shape will give a higher compactness index than a fragment which splits up into several long, thin tree rows reaching into open habitat). The connectivity of a fragment was measured as the distance to the nearest forested patch with a compactness index higher than the minimum compactness we found for the Ecuadorian Tapaculo and with an area $\geq 5$ ha, what we assumed to be large enough to hold a source population for emigration (see Castellón and Sieving 2006).

\section{Patch occupancy model and population extrapolation on a large scale}

Using the map of forested habitats created from satellite images and the coordinates of the territories located in the study area, we determined the minimum size, compactness and connectivity of fragments that are suitable for Ecuadorian Tapaculos in ArcMap 10.2. To estimate the total number and density of territories, we first determined the total area that was searched in the fragments by multiplying the length of the transects by $120 \mathrm{~m}$ width $(60 \mathrm{~m}$ on each side of the transect). Then we evaluated territory density within this area. Using this value, we extrapolated the 
number of territories in areas which were not covered by playback, but suitable according to their landscape metrics. With the help of altitudinal contour lines, the forest fragments in the area covered by satellite images were assigned to elevation zones.

Based on the minimum values for compactness, area and connectivity that were evaluated earlier, we assessed the habitat suitability of a given fragment for Ecuadorian Tapaculos. We then determined the number of territories within a fragment as the area not covered by playback divided by the average territory density. The resulting value gives an estimate for territory numbers based on landscape metrics. To additionally account for density differences as a consequence of variation in habitat quality, we multiplied the extrapolated territory numbers in a given fragment with its value for habitat quality derived from the LDA cross-validation. However, we could not assess habitat quality over the entire species' range. To obtain a sound estimate even though habitat quality was unknown for parts of the range, we extrapolated territory numbers in two steps to the distributional range: First, we developed three different models assuming low, medium or high habitat quality in the fragments we did not visit in the area covered by our satellite images (Figure 1 ). In the medium quality model, we multiplied territory numbers by the mean posterior value for habitat quality in all fragments, as obtained from the LDA. For the low habitat quality model, we multiplied territory numbers by the mean posterior value minus its standard deviation; for the high-quality model, territory numbers were multiplied by the mean posterior value plus one standard deviation. As we did not have satellite images for the northern part of the distribution range, we based the second step of the extrapolation only on the geographical area of the distribution range, assuming a similar distribution of forest fragments. We inferred the global population size by projecting the minimum, medium and maximum quality models to the entire range.

In a subsequent analysis, we assessed which factors influenced the suitability of a fragment as habitat for the Ecuadorian Tapaculo. To this aim, we created a logistic regression model, with the presence or absence of a territory as dependent variable and forest size, compactness, connectivity and habitat suitability as well as the two-way interactions between them as independent variables.

\section{Results}

\section{Territory density}

In contrast to the previously known altitudinal distribution (700-1,250 m), Ecuadorian Tapaculos occurred only between $870 \mathrm{~m}$ and 1,460 $\mathrm{m}$, with a mean of 1,170 $\mathrm{m} \pm 130 \mathrm{~m}$ (Figure 3). Based on these indications, we determined the Ecuadorian Tapaculo's distribution range to extend over an area of about $1,100 \mathrm{~km}^{2}$ in the provinces of El Oro, Azuay and Cañar, in an altitudinal band between $850 \mathrm{~m}$ and $1,500 \mathrm{~m}$ (Figure 1 ).

Overall, we discovered 113 Ecuadorian Tapaculo territories in our study area (Figure 2 indicates territory locations). A total area of 835 ha in forests between 850 and $1,500 \mathrm{~m}$ was covered by playback. The smallest fragment with a territory had a size of 2.29 ha (mean 28.52 ha, max $1,856.99$ ha) whereas mean density was one territory per 7.39 ha of forest. The minimum compactness index for a fragment occupied by a territory was 37.03 (mean 95.59, max 174.94), and the maximum distance between an occupied fragment and the nearest fragment larger than 5 ha was $245 \mathrm{~m}$ (mean $81.79 \mathrm{~m}$, min $10 \mathrm{~m}$ ).

\section{Microhabitat structure on a small scale}

The first four PCs of the PCA accounted for $72.10 \%$ of the total variance in the 11 microhabitat variables (Table 1). Original variables with loadings above a threshold of 0.375 were assigned to the respective PC. PC 1 described the vegetation density in the undergrowth $(0-150 \mathrm{~cm})$, whereas $P C_{2}$ mainly characterised tree features (tree height and diameter in breast height) and terrain inclination. 


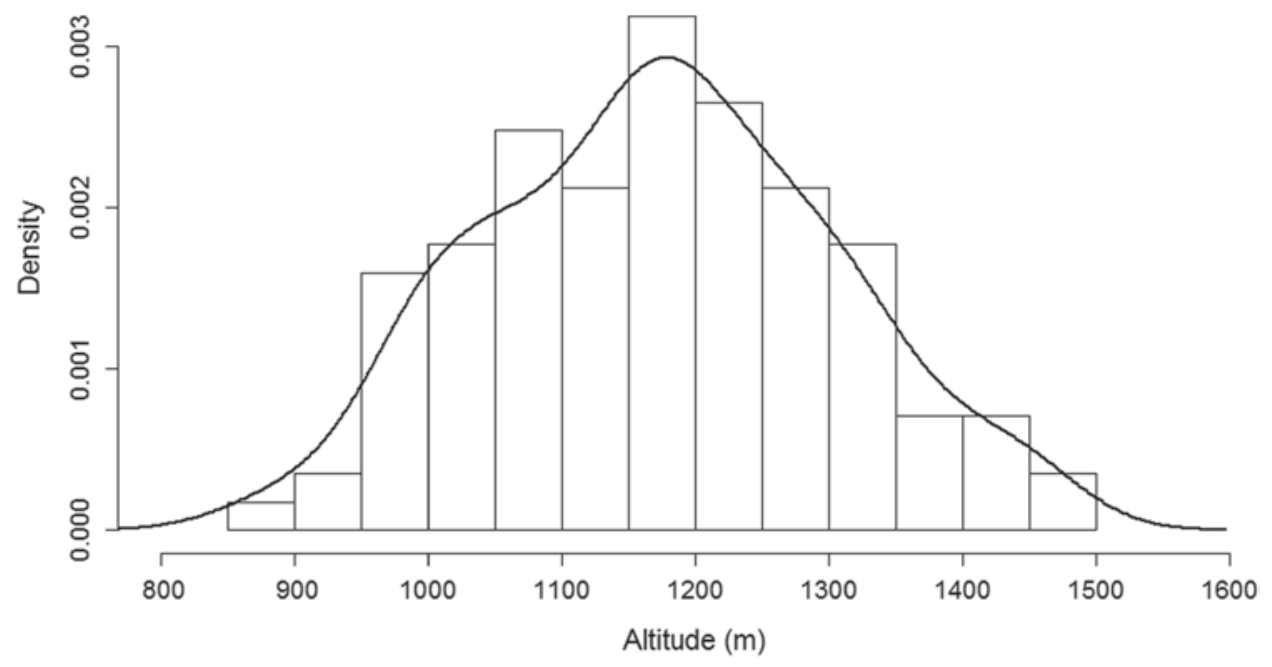

Figure 3. Histogram of the altitudinal distribution of the Ecuadorian Tapaculo in southwestern Ecuador with density curve. The species was found between 870 and 1,460 m (mean 1,170 m).

$\mathrm{PC}_{3}$ represented once again tree characteristics (tree basal area and diameter at breast height) as well as vegetation density in $0-50 \mathrm{~cm}$. $\mathrm{PC}_{4}$ described the number of trees and crown density.

\section{Habitat requirements and habitat suitability on a medium scale}

The logistic regression model of microhabitat structure revealed that PC $2(P<0.001)$ and PC 4 $(P=0.001)$, representing number, height and diameter of trees, crown density and terrain inclination, were the strongest predictors of the presence of a territory. Territories had lower values for PC 2 than control plots (Mann-Whitney U-test: -0.702 vs. $0.546, W=754, P<0.001$ ), indicating that Ecuadorian Tapaculos prefer microhabitats with large trees, big trunks and a strong inclination. Moreover, territories were characterized by lower values for PC 4 (Mann-Whitney U-test: -0.459 vs. $0.357, W=756, P<0.001$ ). This means that territories have more trees than control areas, but a lower density in the crown layer.

The LDA produced similar results. Territories of Ecuadorian Tapaculos and control plots differed in their microhabitat structure (Wilks' Lambda $=0.60, P<0.0001$ ). We defined 0.04 as the threshold for variable coefficients that strongly contributed to identify territories. Territories were characterised by the number and height of trees and by the presence of streams, while the presence of coarse woody debris (e.g. fallen trees or large branches) described control plots (Table 2). Cross-validating the LDA correctly classified $80.34 \%$ of the plots $(75.61 \%$ of territories and $82.89 \%$ of the control plots) to their original group. In the cross-validation of the LDA, the mean probability for a plot to be classified as a territory was $0.34 \pm 0.25$.

The logistic regression of landscape metrics and habitat quality revealed that the connectivity between fragments determined the suitability of a fragment as Tapaculo habitat $(P=0.028)$, followed by the interaction between connectivity and habitat quality $(P=0.034)$ and the interaction between connectivity and fragment compactness $(P=0.044)$.

\section{Patch occupancy model and population extrapolation on a large scale}

The model for medium habitat quality produced 505 territories, equivalent to 1,010 mature individuals for the area covered by the satellite photos. Respectively, the low habitat quality model 
Table 2. Linear discriminant coefficients for the microhabitat variables. Positive values (threshold: 0.04; bold font) describe Ecuadorian Tapaculo territories, and negative values (threshold: -0.04; bold font) describe control plots.

\begin{tabular}{lc}
\hline Habitat variable & Linear discriminant coefficient \\
\hline Inclination $\left[^{\circ}\right]$ & 0.017 \\
Tree height [m] & $\mathbf{0 . 1 0 1}$ \\
DBH [cm] & 0.002 \\
Number of trees & $\mathbf{0 . 5 0 0}$ \\
Density in O-50 cm [\%] & 0.013 \\
Density in 100-150 cm [\%] & 0.014 \\
Woody debris & $\mathbf{- 0 . 4 1 4}$ \\
Streams & $\mathbf{0 . 0 4 7}$ \\
Canopy density [\%] & -0.001 \\
\hline
\end{tabular}

yielded 297 territories, (594 mature individuals). The high habitat quality model resulted in 721 territories, or 1,442 mature individuals.

In a second step, we extrapolated territory numbers to the global range. The medium habitat quality model amounted to 1,610 territories (3,220 mature individuals), while the low habitat quality model yielded 947 territories ( 1,894 mature individuals) and the high habitat quality model 2,299 territories (4,598 mature individuals).

\section{Discussion}

In this study, we modelled the population size and territory characteristics of a threatened understorey bird, the Ecuadorian Tapaculo. In a detailed survey carried out in an area of $190 \mathrm{~km}^{2}$ in the southern part of the distribution range, we discovered a total of 113 territories. Extrapolating habitat quality and territory numbers to the global range revealed that the population size is lower than the previous estimate, which was based upon the geographical range only (Birdlife International 2016). Moreover, we found that the species occurs at higher elevations than thus far known. Within the distributional range of the Ecuadorian Tapaculo, there are almost no primary forests remaining. Ecuadorian Tapaculos prefer mature secondary forests over younger secondary forests. Connectivity between forest fragments is the strongest determinant of whether Ecuadorian Tapaculos occupy a fragment.

\section{Habitat requirements}

Forests in the Tumbes-Chocó-Magdalena hotspot are suffering from extensive logging and habitat degradation. Throughout south-western Ecuador, up to $95 \%$ of the original primary forest had been cut already 25 years ago (Gentry 1992), with only small fragments in different successional stages remaining. Analysing the microhabitat structure in the distribution range of the Ecuadorian Tapaculo allowed us to determine the successional stage of a forest fragment. Forests in the Buenaventura Reserve vary mainly in vegetation density in the understorey, tree height and diameter, canopy density, tree basal area, the number of trees and terrain inclination. The first five of these parameters are structural characteristics used to assess the stage of forest succession. In old-growth or old secondary stands, the vegetation density in the understorey layer is low, whereas younger forests are characterised by a higher density in this layer (DeWalt et al. 2003, Faria et al. 2009). Likewise, the highest basal area as well as very large trees can only be found in older stands (Guariguata and Ostertag 2001, Montgomery and Chazdon 2001, De Avila et al. 2015). Older forests have a lower canopy density, with frequent gaps in the canopy layer (Guariguata and Ostertag 2001). The number of trees however is not clearly related to forest age (DeWalt et al. 2003). In the southern part of the distributional range of the Ecuadorian Tapaculo, 
we did not detect any primary forest. The remaining forest fragments show different gradations of succession.

Comparing the forest structure in territories of Ecuadorian Tapaculos with control plots showed that individuals preferably settled in microhabitats with tall trees having large trunks and a low density of the vegetation in the canopy, which are strong indicators of old-growth or forests in later successional stages. As old forests in this area mainly persist on steep slopes unsuitable for conversion into cattle pastures (Best and Kessler 1995), the apparent preference of the Ecuadorian Tapaculo for strong inclination might be attributable to the unavailability of mature forests in flatter areas. We conclude that the Ecuadorian Tapaculo is restricted to old-growth forests and old secondary stands and is avoiding forests in young successional stages. These findings were additionally confirmed by the linear discriminant analysis, which yielded similar parameters to separate territories and control plots along the discriminant axis over a large spatial area. Thus, the species is indeed heavily threatened by habitat degradation.

Several other closely related species do not show clear preferences for high-quality habitat. Contradictory to our findings, Cuervo et al. (2005) did not detect an effect of tree height or terrain inclination on the presence of Scytalopus stilesi in Colombia. S. latrans, which is widespread throughout the Tumbes-Chocó-Magdalena hotspot, also occurs in heavily disturbed forest fragments (Krabbe et al. 2005). Similarly, the recently discovered S. griseicollis gilesi and S. rodriguezi from Colombia as well as $S$. diamantinensis from Brazil are able to occupy secondary stands at early successional stages (Krabbe et al. 2005, Bornschein et al. 2007, Donegan and Avendaño 2008). The Ecuadorian Tapaculo seems to be less tolerant towards habitat degradation than other species of the same genus. It is also conceivable that habitat degradation throughout the distribution range of the Ecuadorian Tapaculo is greater than in the ranges of the abovementioned species.

Ecuadorian Tapaculos established territories in forests of a late successional stage and avoided younger stands. The species' preference for older secondary forests might be a consequence of the overall poor state of the forests in the distribution range. Assessing habitat quality throughout our study area revealed a mean quality of 0.34 in the study area. This value indicates that only a third of the available forest fragments are suitable for Ecuadorian Tapaculos, suggesting that most forests in the study area are young secondary stands or forests where large old trees were selectively cut. Moreover, we only detected one territory per 7 ha, while the minimum size of a territory was about 0.1 ha. Even though this value might underestimate the actual territory size, the high proportion of habitat which was unoccupied by Ecuadorian Tapaculos indicate its unsuitability for territory establishment. The overall quality of the forest fragments might be so low that the Ecuadorian Tapaculos are confined to the parts providing the highest habitat quality. The fact that habitat quality was partly assessed in the protected Buenaventura Reserve, where the proportion of forests in older successional stages is high, may represent a bias, as the fragments in the remaining range probably have lower habitat quality. Nevertheless, since we detected the biggest population of Ecuadorian Tapaculos in a forest about $5 \mathrm{~km}$ south of the Buenaventura Reserve, the quality in some fragments outside of the reserve is sufficiently high for territory establishment. However, low habitat quality likely presents a limiting factor for the species.

Ecuadorian Tapaculos are dispersal-limited. A logistic regression model revealed that the distance to the nearest large forest patch is the strongest predictor of the presence of Ecuadorian Tapaculos in a fragment. On average, fragments holding territories were separated by clearings of $82 \mathrm{~m}$, with the maximum distance being $245 \mathrm{~m}$. The most isolated fragment holding a territory, which was separated by $245 \mathrm{~m}$ of open habitat from the nearest forest, was at the same time the smallest occupied fragment with an area of about 2 ha. However, only fragments larger than 5 ha are believed to hold a sufficient number of territories for a self-sustaining population of Tapaculos (Castellón and Sieving 2006). Consequently, we consider it likely that the individual that established its territory in this particular fragment had immigrated from the nearest larger fragment, which involved crossing $245 \mathrm{~m}$ of non-forested habitat. A study on Chucao Tapaculos Scelorchilus rubecola discovered that they crossed gaps of up to 120 m width (Castellón and Sieving 2006). 
For the Ecuadorian Tapaculo, exact dispersal data are lacking so far. Deducing from our observational data, we assume $245 \mathrm{~m}$ to be the largest distance an Ecuadorian Tapaculo is able to disperse through clearings.

\section{Range size and population estimates}

Until now, a relatively precise estimate of the population size of the Ecuadorian Tapaculo has been lacking, but the population was suspected to be decreasing rapidly (BirdLife International 2016). Even in the only protected area in its distribution, the Buenaventura Reserve, the species declined, particularly at lower elevations (HMS, pers. obs.). Hence, one aim of our study was to estimate global population size by extrapolating the number of territories located in the study area to the entire range.

In the course of this study, we gained two important new insights into the extent of the species' distribution range. First, the Ecuadorian Tapaculo seems to have undergone a $100 \mathrm{~m}$ upslope range shift at the lower boundary and a $250 \mathrm{~m}$ shift in the upper boundary within the last 25 years. In 1990, the species was discovered at elevations between 700 and 1,250 $\mathrm{m}$ (Krabbe and Schulenberg 1997). Now, we recorded territories only above $870 \mathrm{~m}$, but as high as $1,460 \mathrm{~m}$, which we round here to 850 to $1,500 \mathrm{~m}$. We did not detect any territory between 700 and $870 \mathrm{~m}$, despite the fact that in large parts of the Buenaventura Reserve, the zones below $870 \mathrm{~m}$ are covered by dense forests that appear suitable habitat for Ecuadorian Tapaculos. As such, the potential upslope shift in the lower species boundary is not due to the lack of forest and presumably not an artefact of specific conditions at this site. On the contrary, as the study area contained several different valley systems which yielded similar results, the conclusions drawn from our study can be generalised over a larger area. Although detailed climate data about the region are lacking, forests in the lower parts specifically in the Buenaventura area are reportedly becoming drier (Klauke et al. 2016). This suggests that the potential range shift might be attributable to an altitudinal shift in the cloud bank and therefore humidity, together with a temperature increase. Upslope range shifts as a consequence of climate change have already been observed in other tropical bird species (Freeman and Freeman 2014, Lenoir and Svenning 2014), including the endemic El Oro Parakeet Pyrrhura orcesi, which occupies a similar range as the Ecuadorian Tapaculo (Klauke et al. 2016). It is already known that arid valleys represent distribution boundaries for Andean forest birds, including other Tapaculo species (Krabbe 2008). We therefore consider it likely that the Ecuadorian Tapaculo is shifting its range uphill in order to avoid increasingly dry conditions in the lowerlying areas.

The detection of a territory of an Ecuadorian Tapaculo in the northern Cañar province in February 2015 represents another new finding regarding the distribution range (N. K. Krabbe and F. Sornoza, pers. comm.; see also http://www.xeno-canto.org/241054). Until now, it was assumed that the species would only occur in an area of $1,200 \mathrm{~km}^{2}$ in the cloud forests in El Oro and Azuay provinces (BirdLife International 2016), so the new record implies a range expansion of about $55 \mathrm{~km}$ to the north. Importantly however, we show that even this $55-\mathrm{km}$ expansion of the known range does not extend the earlier estimate of distribution size. The observed upslope shift of the range results in a strong decrease in the net area that was not compensated for by the extension towards the north. Based on these findings, we revised the distribution range of the Ecuadorian Tapaculo, with the species occurring at elevations between 850 and $1,500 \mathrm{~m}$, to an area of $1,100 \mathrm{~km}^{2}$ in El Oro, Azuay, Guayas and Cañar provinces of south-western Ecuador (Figure 1).

The population extrapolation yielded a likely global population size between 1,900 and 4,600 mature individuals. Territory density was highest between about 1,000 and 1,300 $\mathrm{m}$ (Figure 3). For the population extrapolation, we used a conservative estimate of one territory per 7.39 ha, which was derived over the whole elevation range. It is likely that the actual territory density is higher between 1,000 and 1,300 m, while it is lower in the zones above and below this band. Given the specific habitat requirements of the Ecuadorian Tapaculo, we accounted for varying habitat quality when calculating the population size. 
Our results show that the population size of the Ecuadorian Tapaculo is smaller than previously assumed, indicating that the effects of the loss and degradation of its habitat are even more severe than feared. BirdLife International estimates place the Ecuadorian Tapaculo in the band of 2,500 to 9,999 mature individuals and classifies it as 'Endangered' based on population and range size criteria. The species' conservation status was evaluated for the first time in 2007 (BirdLife International 2016); however, in 2003, the species was described as uncommon, but not threatened (Krabbe and Schulenberg 2003). Given our lower, but more precise estimate compared to the one from BirdLife International, it is likely that the decrease in population size in the last decades is more severe than hitherto known. Perhaps most alarmingly, even assuming a high-quality habitat, population numbers are less than half of the previous estimate. In addition, we highlight that the upslope range shift that the species has undergone in the past 25 years and which is accompanied by a reduction in range size, may continue in the future. Continuing deforestation and habitat degradation may reduce the amount of forested habitat and connectivity between fragments further, which will reduce gene flow and the sizes of the remaining populations of this endangered species and other associated biodiversity in the Tumbes-Chocó-Magdalena biodiversity hotspot.

\section{Implications for conservation}

The Ecuadorian Tapaculo is exposed to two major threats: fragmentation and degradation of its habitat, and an upslope range shift. Both threats are inevitably contributing to disrupt connectivity between populations, which can lead to lower migration rates and genetic impoverishment of the species. To ensure the persistence of the Ecuadorian Tapaculo in a rapidly changing environment, conservation actions have to be undertaken to mitigate the above-mentioned negative effects. Our study revealed that the connectivity between fragments, habitat quality and fragment compactness are major predictors of a forest's suitability as habitat for the Ecuadorian Tapaculo. Hence, improvements in these parameters should be the priority target when planning sciencebased conservation measures to increase habitat availability for the Ecuadorian Tapaculo and facilitate dispersal between populations.

The establishment of forested corridors is a reliable method of enabling dispersal of less mobile species (Sieving et al. 2000, Castellón and Sieving 2006, 2007, Lees and Peres 2008). As Ecuadorian Tapaculos are potentially able to cross up to $245 \mathrm{~m}$ of open habitat, we assume this to be the maximum distance between forest fragments that still provides connectivity for the species. However, the majority of fragments containing territories were only separated by gaps of up to $80 \mathrm{~m}$. Consequently, we recommend creating dispersal corridors between remote fragments with the priority aim of reducing the amount of open habitat between them to a maximum of $245 \mathrm{~m}$ and, secondary, to a maximum of $80 \mathrm{~m}$. Considering the high level of fragmentation in the range of the Ecuadorian Tapaculo (Figure 2), the creation of fully forested corridors may not be possible due to money, time, and energy constraints. However, even shrubby vegetation in the matrix (Castellón and Sieving 2006), small forest patches that serve as stepping stones (Uezu et al. 2008), or narrow corridors of about $25 \mathrm{~m}$ width (Sieving et al. 2000) already enhance the movement of understorey birds and may facilitate dispersal between disconnected populations of the Ecuadorian Tapaculo.

Apart from re-establishing connectivity between fragments, improving forest quality and quantity is crucial for the persistence of Ecuadorian Tapaculos. The species is unable to endure in low-quality habitat and requires compact forests that are not subject to extensive edge-effects. Owing to the dramatic deforestation rates in south-western Ecuador, forest patches are mainly composed of young secondary stands that are unsuitable as habitat for the species. Hence, it is crucial to initiate conservation measures focusing on improving forest quality and protecting older forests within the distribution range. Studies conducted in Costa Rica and Panama revealed that secondary forests recover within a few decades (Aide et al. 2000, DeWalt et al. 2003). Even abandoned cattle pastures have the ability to regain characteristics of primary forests (Aide et al. 1995, 2000). Habitat management can further accelerate the recovery process. Depending on the level of degradation, reforesting native trees facilitates the reestablishment of the original forest ecosystem (Holl et al. 2000, Lamb et al. 2005). 
While forest recovery and the restoration of connectivity between disconnected populations of the Ecuadorian Tapaculo can be influenced by the implementation of sound conservation actions, the upslope range shift is likely caused by climate change and therefore less foreseeable. Global warming is most likely not preventable in the near future. Given that within the last 25 years, the Ecuadorian Tapaculo apparently migrated uphill at a rate of up to $100 \mathrm{~m}$ per decade, it is possible that the upslope shift is still an ongoing process and the species is further driven to even higher elevations. Whether the range shift will continue at the same speed, will be slowed down or even accelerate remains unclear. In view of ongoing deforestation and, potentially, a further upslope shift in the distribution range, it will be crucial to protect remaining forest fragments not only in today's range of the Ecuadorian Tapaculo, but also in elevations that by now exceed the range but may be invaded by the species within the next decades. Here, reforestation actions to enable effective dispersal between populations have to be implemented. Given that the Ecuadorian Tapaculo has low dispersal abilities and, at the same time, specific demands for high-quality habitat, conservation measures to restore connectivity between different populations will be beneficial for the dispersal of a variety of other Tumbes-Chocó-Magdalena species as well.

\section{Supplementary Material}

To view supplementary material for this article, please visit https://oi.org/10.1017/ So95927091600054X

\section{Acknowledgements}

We thank Annika Döpper, Arne Pinnschmidt and Hannes Kampf for their great assistance in field work. We are grateful to Niels Krabbe for his valuable advice during the development of the project. Moreover, we thank Niels Krabbe and Francisco Sornoza for providing the coordinates of the territory found in Cañar. César Garzón kindly provided the satellite images of the study area. We thank Fundación Jocotoco for logistic support during field work, and the landowners in the study area for granting us access to their properties. Permission to conduct field work (No. oo5-IC-FAN-DPEO-MAE) was granted by the Ministerio de Ambiente, Ecuador. This work was supported by the Mohamed bin Zayed Species Conservation Fund (C.H., grant number 13257994); and Sweden Clubzoo Bird Protection (C.H.).

\section{References}

Aide, T. M., Zimmerman, J. K., Herrera, L. Rosario, M. and Serrano, M. (1995) Forest recovery in abandoned tropical pastures in Puerto Rico. For. Ecol. Manag. 77: 77-86.

Aide, T. M., Zimmerman, J. K., Pascarella, J. B., Rivera, L. and Marcano-Vega, H. (200o) Forest regeneration in a chronosequence of tropical abandoned pastures: Implications for restoration ecology. Restor. Ecol. 8: 328-338.

Amico, G. C., Garcia, D. and Rodriguez-Cabal, M. A. (2008) Spatial structure and scaledependent microhabitat use of endemic "tapaculos" (Rhinocryptidae) in a temperate forest of southern South America. Ecología Austral 18: 169-180.

Beissinger, S. R., Wunderle, J. M., Meyers, J. M., Saether, B. E. and Engen, S. (2008)
Anatomy of a bottleneck: Diagnosing factors limiting population growth in the Puerto Rican Parrot. Ecol. Monogr. 78: 185-203.

Best, B. J. and Kessler, M. (1995) Biodiversity and conservation in Tumbesian Ecuador and Peru. Cambridge, UK: BirdLife International.

BirdLife International (2016) Species Factsheet: Scytalopus robbinsi. http://www.birdlife.org. Downloaded I March 2016.

Bornschein, M. R., Nachtigall, M. G., BelmonteLopes, R., Mata, H. and Bonatto, S. L. (2007) Diamantina Tapaculo, a new Scytalopus endemic to the Chapada Diamantina, northeastern Brazil (Passeriformes: Rhinocryptidae). Rev. Brasileira Ornitol. 15: 151-174. 
Brook, B. W., Sodhi, N. S. and Bradshaw, C. J. A. (2008) Synergies among extinction drivers under global change. Trends Ecol. Evol. 23: 453-46o.

Brooks, T. M., Mittermeier, R. A., Mittermeier, C. G., Da Fonseca, G. A. B., Rylands, A. B., Konstant, W. R., Flick, P., Pilgrim, J., Oldfield, S., Magin, G. and Hilton-Taylor, C. (2002) Hotspots: Earth's biologically richest and most endangered terrestrial ecoregions. Conserv. Biol. 16: 909-923.

Castellón, T. D. and Sieving, K. E. (2006) An experimental test of matrix permeability and corridor use by an endemic understory bird. Conserv. Biol. 20: 135-145.

Castellón, T. D. and Sieving, K. E. (2007) Patch network criteria for dispersal-limited endemic birds of South American temperate rain forest. Ecol. Applic. 17: 2152-2163.

Coulon, A., Guillot, G., Cosson, J. F., Angibault, J. M. A., Aulagnier, S., Cargnelutti, B., Galan, M. and Hewison, A. J. M. (2006) Genetic structure is influenced by landscape features: Empirical evidence from a roe deer population. Mol. Ecol. 15: 1669-1679.

Cuervo, A. M., Cadena, C. D., Krabbe, N. K. and Renjifo, L. M. (2005) Scytalopus stilesi, a new species of Tapaculo (Rhinocryptidae) from the Cordillera Central of Colombia. Auk 122: 445-463.

De Avila, A. L., Ruschel, A. R., De Carvalho, J. O. P., Mazzei, L., Macedo Silva, J. N., Lopes, J. D., Machado Araujo, M., Dormann, C. F. and Bauhus, J. (2015) Medium-term dynamics of tree species composition in response to silvicultural intervention intensities in a tropical rain forest. Biol. Conserv. 191: 577-586.

De Santo, T. L., Willson, M. F., Sieving, K. E. and Armesto, J. J. (2002) Nesting biology of Tapaculos (Rhinocryptidae) in fragmented south-temperate rainforests of Chile. Condor 104: 482-495.

DeWalt, S. J., Maliakal, S. K. and Denslow, J. S. (2003) Changes in vegetation structure and composition along a tropical forest chronosequence: Implications for wildlife. For. Ecol. Manag. 182: 139-151.

Donegan, T. M. and Avendaño, J. E. (2008) Notes on Tapaculos (Passeriformes: Rhinocryptidae) of the eastern Andes of Colombia and the Venezuelan Andes, with a new subspecies of Scytalopus griseicollis from Colombia. Ornitol. Colombiana 6: 24-65.

Duncan, R. P. and Blackburn, T. M. (2004) Extinction and endemism in the New Zealand avifauna. Glob. Ecol. Biogeogr. 13: 509-517.

Epps, C. W., Palsbøll, P. J., Wehausen, J. D., Roderick, G.K., Ramey, R. R. and McCullough, D. R. (2005) Highways block gene flow and cause a rapid decline in genetic diversity of desert bighorn sheep. Ecol. Lett. 8: 1029-1038.

FAO (2010) Global forest resources assessment. Main report. Rome, Italy: Food and Agriculture Organization of the United Nations. (FAO Forestry Paper 163).

Fagan, W. F. and Holmes, E. E. (2006) Quantifying the extinction vortex. Ecol. Lett. 9: 51-60.

Faria, D., Mariano-Neto, E., Zanforlin Martini, A. M., Ortiz, J. V., Montingelli, R., Rosso, S, Barradas Paciencia, M. L. and Baumgarten, J. (2009) Forest structure in a mosaic of rainforest sites: The effect of fragmentation and recovery after clear cut. For. Ecol. Manag. 257: 2226-2234.

Feeley, K. J., Silman, M. R., Bush, M. B., Farfan, W., Garcia Cabrera, K., Malhi, Y., Meir, P., Salinas Revilla, N., Raurau Quisiyupanqui, M. N. and Saatchi, S. (2011) Upslope migration of Andean trees. J. Biogeogr. 38: 783-791.

Foster, P. (2001) The potential negative impacts of global climate change on tropical montane cloud forests. Earth-Sci. Rev. 55: 73-106.

Freeman, B. G. and Freeman, A. M. C. (2014) Rapid upslope shifts in New Guinean birds illustrate strong distributional responses of tropical montane species to global warming. Proc. Nat. Acad. Sci. USA 111: 4490-4494.

Freile, J. F. and Santander, T. (2005) Áreas importantes para la conservación de las aves en Ecuador in: Áreas importantes para la conservación de las aves en los Andes tropicales: Sitios prioritarios para la conservación de la biodiversidad. Quito, Ecuador: BirdLife International and Conservation International. (Serie de conservación No. 14). Gentry, A. H. (1992) Tropical forest biodiversity: Distributional patterns and their conservational significance. Oikos 63: 19-28. 
Guariguata, M. R. and Ostertag, R. (2001) Neotropical secondary forest succession: Changes in structural and functional characteristics. For. Ecol. Manag. 148: 185-206.

Holl, K. D., Loik, M. E., Lin, E. H. V. and Samuels, I. A. (2000) Tropical montane forest restoration in Costa Rica: overcoming barriers to dispersal and establishment. Restor. Ecol. 8: 339-349

Keller, L. F. and Waller, D. M. (2002) Inbreeding effects in wild populations. Trends Ecol. Evol. 17: 230-241.

Klauke, N., Schaefer, H. M., Bauer, M. and Segelbacher, G. (2016) The influence of natural habitat structure and habitat disturbance on the fine-scale genetic structure of an endemic Neotropical parrot. PLoS One I1(12): e0169165. https://doi.org/10.1371/ journal.pone.0169165

Kleman, L. Jr. and Vieira, J. S. (2013) Assessing the extent of occurrence, area of occupancy, territory size, and population size of Marsh Tapaculo (Scytalopus iraiensis). Anim. Biodivers. Conserv. 36: 47-57.

Krabbe, N. K. (2008) Arid valleys as dispersal barriers to high-Andean forest birds in Ecuador. Cotinga 29: 28-30.

Krabbe, N. K. and Schulenberg, T. S. (1997) Species limits and natural history of Scytalopus Tapaculos (Rhinocryptidae), with descriptions of the Ecuadorian taxa, including three new species. Ornithol. Monogr. 48: 47-88.

Krabbe, N. K. and Schulenberg, T. S. (2003) Family Rhinocryptidae (Tapaculos). Pp. 748787 in J. Del Hoyo, A. Elliott, D. A. Christie, eds. Handbook of the birds of the world. Vol. 8. Broadbills to tapaculos. Barcelona, Spain: Lynx Edicions.

Krabbe, N. K., Salaman, P., Cortés, A., Quevedo, A., Ortega, L. A. and Cadena, C. D. (2005) A new species of Scytalopus tapaculo from the upper Magdalena Valley, Colombia. Bull. Br. Ornithol. Club 125: 93-108.

Lamb, D., Erskine, P. D. and Parrotta, J. A. (2005) Restoration of degraded tropical forest landscapes. Science 310: 1628-1632.

LaVal, R. K. (2004) Impact of global warming and locally changing climate on tropical cloud forest bats. J. Mammal. 85: 237-244.

Lees, A. C. and Peres, C. A. (2008) Conservation value of remnant riparian forest corridors of varying quality for Amazonian birds and mammals. Conserv. Biol. 22: 439-449.

Lenoir, J. and Svenning, J. C. (2014) Climaterelated range shifts - a global multidimensional synthesis and new research directions. Ecography 37: 001-014.

Montgomery, R. A. and Chazdon, R. L. (200I) Forest structure, canopy architecture, and light transmittance in tropical wet forests. Ecology 82: 2707-2718.

Morueta-Holme, N., Engemann, K., SandovalAcuña, P., Jonas, J. D., Segnitz, R. M. and Svenning, J. C. (2016) Strong upslope shifts in Chimborazo's vegetation over two centuries since Humboldt. PNAS 112: 12741-12745.

Myers, N., Mittermeier, R. A., Mittermeier, C. G., Da Fonseca, G. A. B. and Kent, J. (2000) Biodiversity hotspots for conservation priorities. Nature 403: 853-858.

Nogué, S., Rull, V. and Vegas-Vilarrúbia, T. (2009) Modeling biodiversity loss by global warming on Pantepui, northern South America: projected upward migration and potential habitat loss. Clim. Change 94: 77-85.

Noss, R. F. and Harris, L. D. (1986) Nodes, networks, and MUMs: Preserving diversity at all scales. Environ. Manag. 10: 299-309.

Parmesan, C. (2006) Ecological and evolutionary responses to recent climate change. Ann. Rev. Ecol. Evol. Systematics 37: 637-669.

Pounds, A. J., Fogden, M. P. L. and Campbell, J. H. (1999) Biological response to climate change on a tropical mountain. Nature 398: 611-615.

Raxworthy, C. J., Pearson, R. G., Rabibisoa, N., Rakotondrazafy, A. M., Ramanamanjato, J. B., Raselimanana, A. M., Wu, S., Nussbaum, R. A. and Stone, D. A. (2008) Extinction vulnerability of tropical montane endemism from warming and upslope displacement: A preliminary appraisal for the highest massif in Madagascar. Glob. Change Biol. 14: 1703-1720.

Reid, S., Diaz, I. A., Armesto, J. J. and Willson, M. F. (2004) Importance of native bamboo for understory birds in Chilean temperate forests. Auk 121: 515-525.

Robbins, M. B. and Ridgely, R. S. (1990) The avifauna of an upper tropical cloud forest in southwestern Ecuador. Proc. Acad. Nat. Sci. Philadelphia 142: 59-71.

Rull, V., Vegas-Vilarrúbia, T. (2006) Unexpected biodiversity loss under global warming 
in the neotropical Guayana Highlands: A preliminary appraisal. Glob. Change Biol. 12: 1-9.

Segelbacher, G., Cushman, S. A., Epperson, B. K., Fortin, M. J., Francois, O., Hardy, O. J., Holderegger, R., Taberlet, P., Waits, L. P. and Manel, S. (2010) Applications of landscape genetics in conservation biology: concepts and challenges. Conserv. Genet. 11: $375-385$.

Sieving, K. E., Willson, M. F. and De Santo, T. L. (1996) Habitat barriers to movement of understory birds in fragmented southtemperate rainforest. Auk 113: 944-949.

Sieving, K. E., Willson, M. F. and De Santo, T. L. (2000) Defining corridor functions for endemic birds in fragmented southtemperate rainforest. Conserv. Biol. 14: $1120-1132$.

Sodhi, N. S., Liow, L. H. and Bazzaz, F. A. (2004) Avian extinctions from tropical and subtropical forests. Annu. Rev. Ecol. Evol. Syst. 35: 323-345.

Still, C. J., Foster, P. N. and Schneider, S. H. (1999) Simulating the effects of climate change on tropical montane cloud forests. Nature 398: 608-610.

Uezu, A., Beyer, D. D. and Metzger, J. P. (2008) Can agroforest woodlots work as stepping stones for birds in the Atlantic forest region? Biodivers. Conserv. 17: 1907-1922.

\section{CLAUDIA HERMES ${ }^{2 *}$, JEROEN JANSEN, H. MARTIN SCHAEFER ${ }^{1}$}

Department of Animal Ecology and Evolution, Faculty of Biology, University of Freiburg, Hauptstrasse 1, D-79104 Freiburg, Germany.

${ }^{1}$ and Fundación Jocotoco, Lizardo García E9-104 y Andrés Xaura, P.O. Box 17-16-337, Quito, Ecuador.

${ }^{2}$ Chair of Wildlife Ecology and Management, Faculty of Environment and Natural Resources, University of Freiburg, Tennenbacher Strasse 4, D-79106 Freiburg, Germany.

*Author for correspondence; e-mail:claudia.hermes@wildlife.uni-freiburg.de 